\title{
Nonlinear Aeroelastic Simulation of X-HALE: a Very Flexible UAV
}

\author{
Carlos E. S. Cesnik ${ }^{1}$ and Weihua $\mathrm{Su}^{2}$ \\ University of Michigan, Ann Arbor, MI 48109-2140
}

\begin{abstract}
A very flexible unmanned aerial vehicle has been designed and manufactured at the University of Michigan. The vehicle is named X-HALE, whose flight tests are expected to provide important data of its geometrically nonlinear aeroelastic behavior coupled with the six rigid-body degrees of freedom. As the target of the aeroelastic design, the X-HALE vehicle will present unstable aeroelastic/flight dynamic behavior when subjected to finite disturbances. To design such behavior in the aircraft, nonlinear aeroelastic simulations of $X$ HALE were performed using the University of Michigan's Nonlinear Aeroelastic Simulation Toolbox (UM/NAST), which provides an estimation of the vehicle's flight characteristics. The simulation cases include the achievement of the target aeroelastic/flight dynamic instability and the arrestment of the unstable motion without using a dedicated closed-loop control scheme.
\end{abstract}

\section{Introduction}

$\mathrm{R}$ ECENT advances in airborne sensors and communication packages are requiring new air platforms that can stay at station for very long periods of time. The missions may include intelligence, surveillance, and reconnaissance (ISR) for the military ${ }^{1}$, network communication nodes for the military and civilian usage, and general atmospheric research ${ }^{2}$. Because of the mission requirements, the aircraft platforms are characterized by high-aspect-ratio wings and, if existent, slender fuselages, resulting in very flexible vehicles. Improved mission capabilities such as longer loiter times, heavier payload, greater range, etc. drive the demand for greater aerodynamic performance on those systems. Enhanced airframe performance is generally achieved through lightweight, flexible solutions. Modern high-altitude long-endurance (HALE) aircraft designs have become so lightweight and flexible that traditional (linear) design methods are no longer adequate and nonlinear aeroelastic design methods are required to characterize structural and aeroelastic designs (Ref. 3). The wings may undergo large deformations during normal operating loads, exhibiting geometrically nonlinear behavior (Fig. 1). Engineering analysis on very flexible vehicles will need to include geometrically nonlinear structural models for the primary structures to capture any large deformations that may appear under operational loads. In addition to large deformations, a second characteristic of very flexible aircraft will be very low frequencies of their natural structural vibration modes. Due to this, it should be expected a strong coupling between the structural dynamics and the rigidbody (flight dynamic) characteristics of the vehicle.

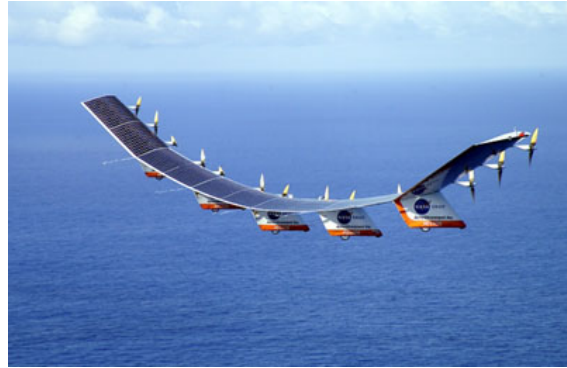

Figure 1. Aerovironment's Helios showing large wing deflection (Courtesy NASA Dryden).

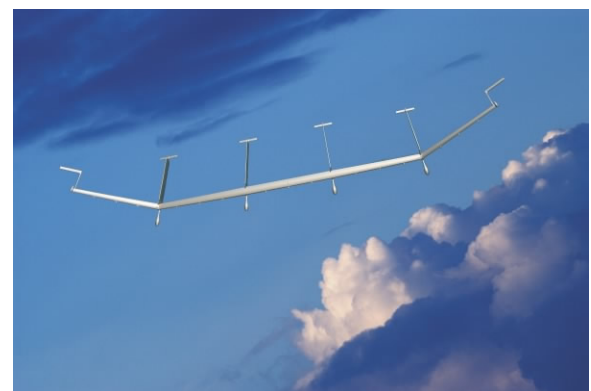

Figure 2. DARPA/Boeing's Vulture II (Courtesy Boeing Co.).

\footnotetext{
${ }^{1}$ Professor (cesnik@umich.edu), Department of Aerospace Engineering, Associate Fellow AIAA.

${ }^{2}$ Post-doctoral Research Fellow (suw@umich.edu), Department of Aerospace Engineering, Senior Member AIAA.
} 
More recently, Aurora Flight Sciences, Boeing Co., and Lockheed-Martin Co. have developed studies for extreme-long duration HALE concepts ${ }^{4}$. Boeing Co., under DARPA's Vulture II program, will be designing and flight demonstrating a very flexible aircraft (Fig. 2). The combination of high aerodynamic efficiency and low structural weight fraction yields inherently flexible wings and nonlinear structural and flight dynamics. HALE aircraft are expected to be susceptible to large dynamic wing deformations at low frequencies, presenting a direct impact into the flight dynamic characteristics of the vehicle, as was seen in the Helios flight tests.

Nonlinear aeroelastic solvers have been under development to improve predictions of aircraft response, stability, and overall performance ${ }^{6-15}$. The body of work in the literature associated with the problem of nonlinear aeroelasticity coupled with nonlinear flight dynamics started developing at earnest in the 1990's. An overview of those can be found in Refs. 11, 12, 16. Among the handful of comprehensive formulation for very flexible aircraft analysis, Cesnik and his co-workers have developed a novel and practical solution to the coupled nonlinear aeroelasticity and flight dynamics of very flexible aircraft. With the focus on a reduced number of states to represent the complex nonlinear problem, the framework, named the University of Michigan's Nonlinear Aeroelastic Simulation Toolbox (UM/NAST), provides a suitable plant representation for control design. Several aeroelastic issues in high-altitude long-endurance aircraft have been addressed, including nonlinear aeroelastic modeling ${ }^{9,11}$, integral wing actuation for generating maneuver loads ${ }^{17,18}$, flutter boundary enhancement ${ }^{19}$, gust load alleviation ${ }^{20}$, and overall nonlinear vehicle optimization of unconventional configurations ${ }^{17}$.

All these numerical efforts must eventually be validated against experimental data so that they can be applied to new HALE aircraft concepts. The various components of most of the existing codes have been partially validated with limited experimental data coming from bench (e.g., Refs. 21-23) and/or small-scale wind tunnel tests (e.g., Refs. 24 and 25). Some of the discipline components have also been compared against well-established numerical solutions (e.g., nonlinear composite beam analyses, rigid flight dynamics, and computational fluid dynamics). However, there has been no validation of the integrated solution that brings the coupling effects between nonlinear aeroelasticity and flight dynamics, since no data is available for such exercise.

An effort to design, build, and flight test a very flexible, remotely piloted aircraft has been on-going at the University of Michigan, with participation of the Air Force Institute of Technology and the support of the Air Force Research Laboratory. The Experimental HALE (X-HALE) aircraft is being developed as a low cost platform to obtain relevant nonlinear aeroelastic data to support validation of nonlinear aeroelastic codes - and also as future platform for control law studies. Ultimately, the X-HALE project will provide open source/benchmark-type data for aircraft construction, ground and flight (open/close-loop) test results.

The vehicle must be able to capture unique coupled nonlinear aeroelasticity/flight dynamics interactions not easily obtained/possible from wind tunnel tests. And the key requirements imposed from the outset of the design are:

- Well-characterized structural, aerodynamics, propulsive vehicle properties;

- Enough control authority to excite various flight conditions;

- Capable of static wing deformations on the order of $30 \%$ tip deflection;

- More than 30 minutes flight endurance.

This paper presents a study on the X-HALE design and its nonlinear aeroelastic stability characteristics by means of simulations from UM/NAST. Since its unstable behavior under finite disturbances was designed into the vehicle, it is also important to be able to bring the aircraft out of that unstable condition during flight tests. The single push-button solution that does not involve potential pilot induced oscillation in attempt to control the plane is presented and simulated accordingly. This paper shows that the proposed design should be able to develop a lateral instability based on a coupled Dutch-roll and wing bending, therefore providing unique data in support to code validation not available in the literature.

\section{Overview of the Design of X-HALE}

The primary purpose of X-HALE is to validate nonlinear aeroelastic and flight simulation software. To satisfy this, the systems design and layout must produce an airframe that is consistent and measurable in both real and simulated flight. This is the most unique and challenging aspect of the X-HALE concept as it complicates three of X-HALE's primary subsystems: the wing structure, electronics, and software. Structurally, the wing must be idealized and fabricated as a consistent composite beam to create a representative simulated model. To gather the required strain, control input, and flight condition data a complex array of sensors and supporting data acquisition hardware and software must be integrated without impacting the wing's structural properties. A detailed design process was described in Ref. 16. This section will only give an over view of the platform and some essential components in the numerical nonlinear aeroelastic simulations. 


\section{A. Airframe Layout}

The X-HALE is a flexible, high aspect ratio wing-boom-tail type aircraft. It has an 8-m span (constructed with eight identical $1-\mathrm{m}$ sections), $0.2-\mathrm{m}$ chord, four $0.83-\mathrm{m}$ booms with $0.475-\mathrm{m}$ horizontal tails attached, and five motor pods with propellers, batteries, and processor boards (Fig. 3). X-HALE has a mass of $11 \mathrm{~kg}$ with an anticipated flight speed ranging from 10 to $19 \mathrm{~m} / \mathrm{s}$. Main vehicle sizing characteristics are given in Table 1 . Pitch and roll will be controlled by the horizontal elevons, and yaw will be controlled using differential thrust from the motors. Disturbances will be applied with schedule all-movable horizontal tail deflections supplemented by ailerons on the dihedral outer wing sections. Those disturbances will excite wing deformation during flight, and its response will be recorded from a series of on-board sensors. Those sensors are a collection of IMU, strain gages, and accelerometers. The readers may refer to Ref. 16 to view the detailed wing, fairing, tail, and electronics designs.

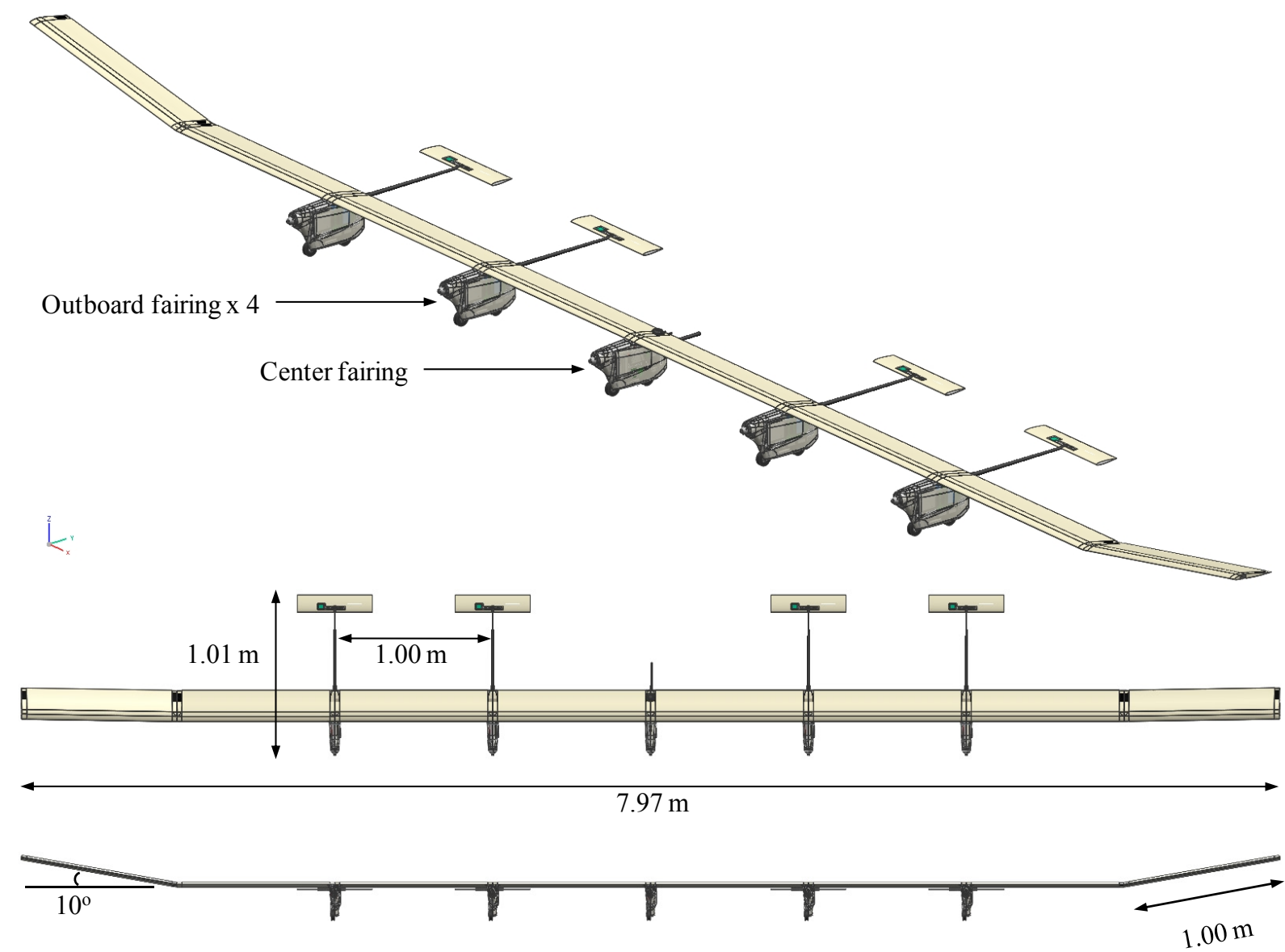

Figure 3. Complete X-HALE CAD assembly: isometric, top, and front views.

\section{B. Airfoil Selection and Characteristics}

One specific aspect in the design and simulation of X-HALE is about its wing and tail's aerodynamic characteristics. The X-HALE design was originally inspired by Aerovironment's Helios aircraft. As a result, the original airframe was a flying wing, which led to reflex type airfoils. Trading the moment coefficient $c_{\mathrm{m} 0}$, stall angle, and the ratio of lift-over-drag, the final choice was to use the EMX07 reflexed airfoil, displayed with its pressure profile in Fig. 4. Once the design progressed, horizontal tails became an alternative to placing control surfaces within the uniform wing structure. NACA 0012 airfoil was chosen because of the standard behavior of the symmetric airfoil.

With a chord of $0.2 \mathrm{~m}$ and $0.12 \mathrm{~m}$, respectively, the wing and tail Reynolds numbers are low, ranging from 150,000 to 93,000 at a $14 \mathrm{~m} / \mathrm{s}$ reference cruise velocity. This has an effect on the aerodynamic derivatives of each airfoil, but is much more significant for the NACA 0012 airfoil. Figures 5 and 6 display the basic aerodynamic coefficients for each airfoil at the operating Reynolds number $(150,000)$. Along with those, results for a high 
Reynolds number of 1,500,000 are included just for comparison. The results displayed in Figs. 5 and 6 indicate the importance of providing customized aerodynamic data to a design and/or analysis process to produce realistic simulation results. Standard aerodynamic derivatives such as $2 \pi$ for lift coefficient curve slop $c_{l \alpha}$ are no longer valid especially for NACA 0012 airfoil, which ranges from 4.4 to 12 depending on the angle of attack. This dependence on angle of attack is translated into the UM/NAST simulations through look-up tables and calibration functions in order to produce the most realistic simulation results. Tables 2 and 3 display the resulting aerodynamic derivatives for both airfoils. All these data were calculated using XFoil. Two-dimensional wind tunnel tests are under way to verify the validity of these properties for the as-manufactured wing and tail sections.

Table 1. X-HALE main characteristics.

\begin{tabular}{lcc}
\hline \hline Wing Span & 8 & $\mathrm{~m}$ \\
Chord & 0.2 & $\mathrm{~m}$ \\
Platform Area & 1.6 & $\mathrm{~m}^{2}$ \\
Aspect Ratio & 40 & -- \\
Length & 0.96 & $\mathrm{~m}$ \\
Propeller Diameter & 0.30 & $\mathrm{~m}$ \\
Max Payload & 7.2 & $\mathrm{~kg}$ \\
Max Gross Takeoff Weight & 11.1 & $\mathrm{~kg}$ \\
Power/Weight & 25.5 & $\mathrm{~W} / \mathrm{kg}$ \\
Airspeed & $10-19$ & $\mathrm{~m} / \mathrm{s}$ \\
Endurance & 45 & $\mathrm{~min}$ \\
\hline \hline
\end{tabular}

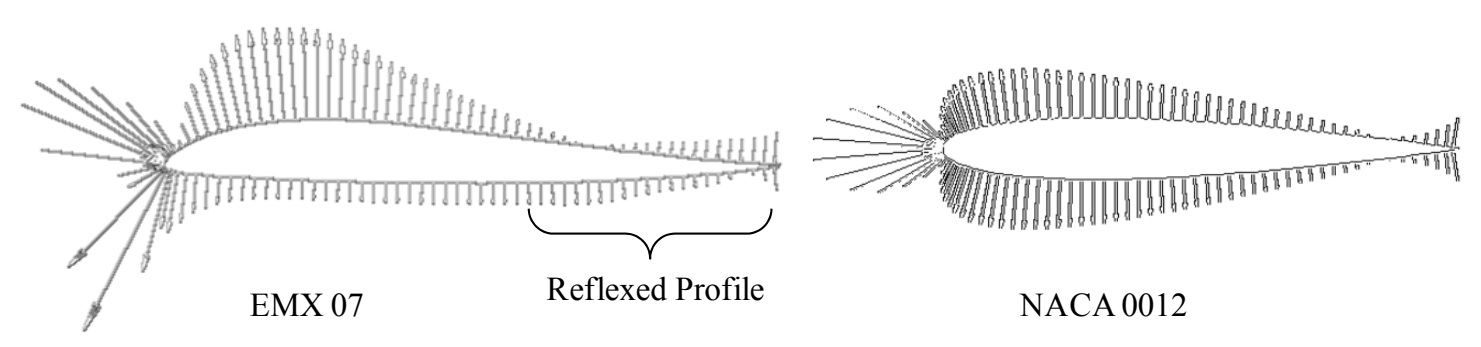

Figure 4. Wing and tail airfoil profiles.
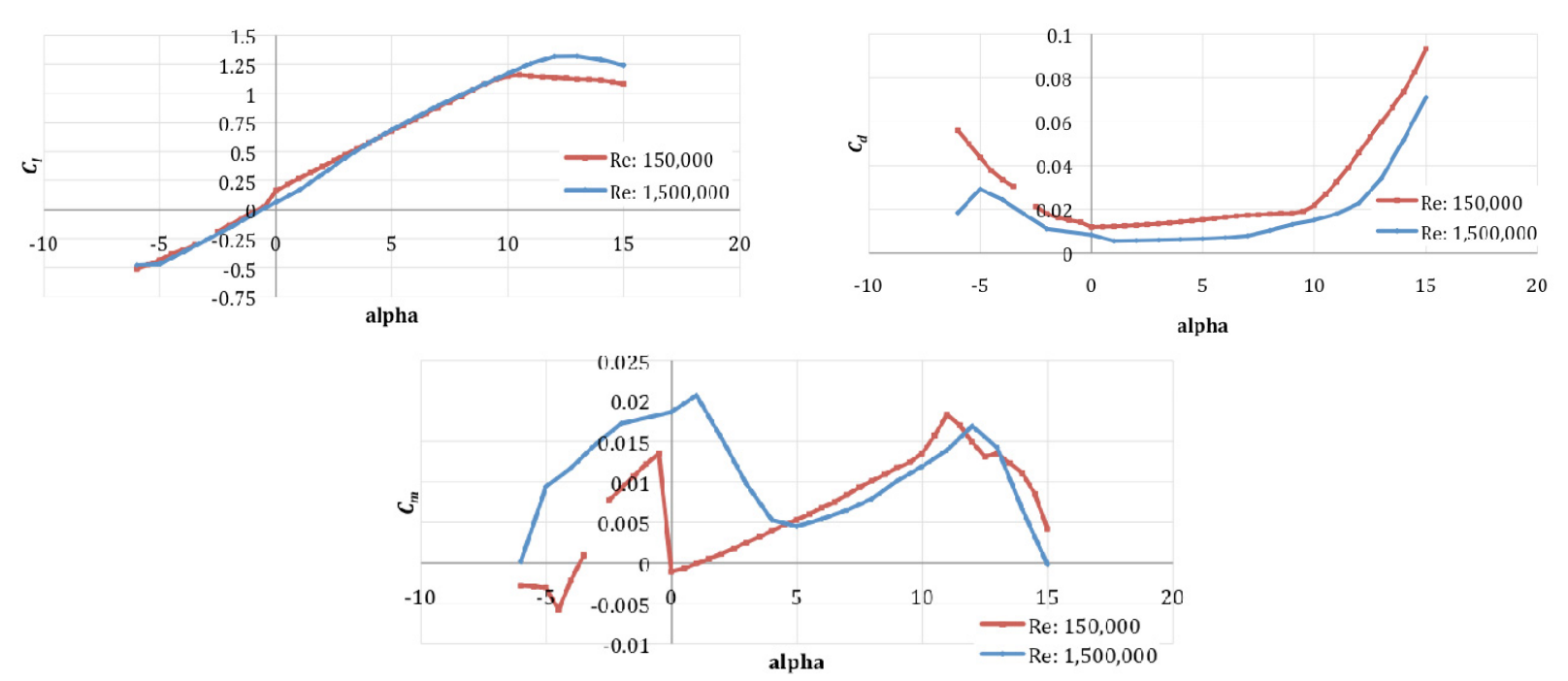

Figure 5. EMX07 airfoil for the main wing (results obtained using XFoil). 

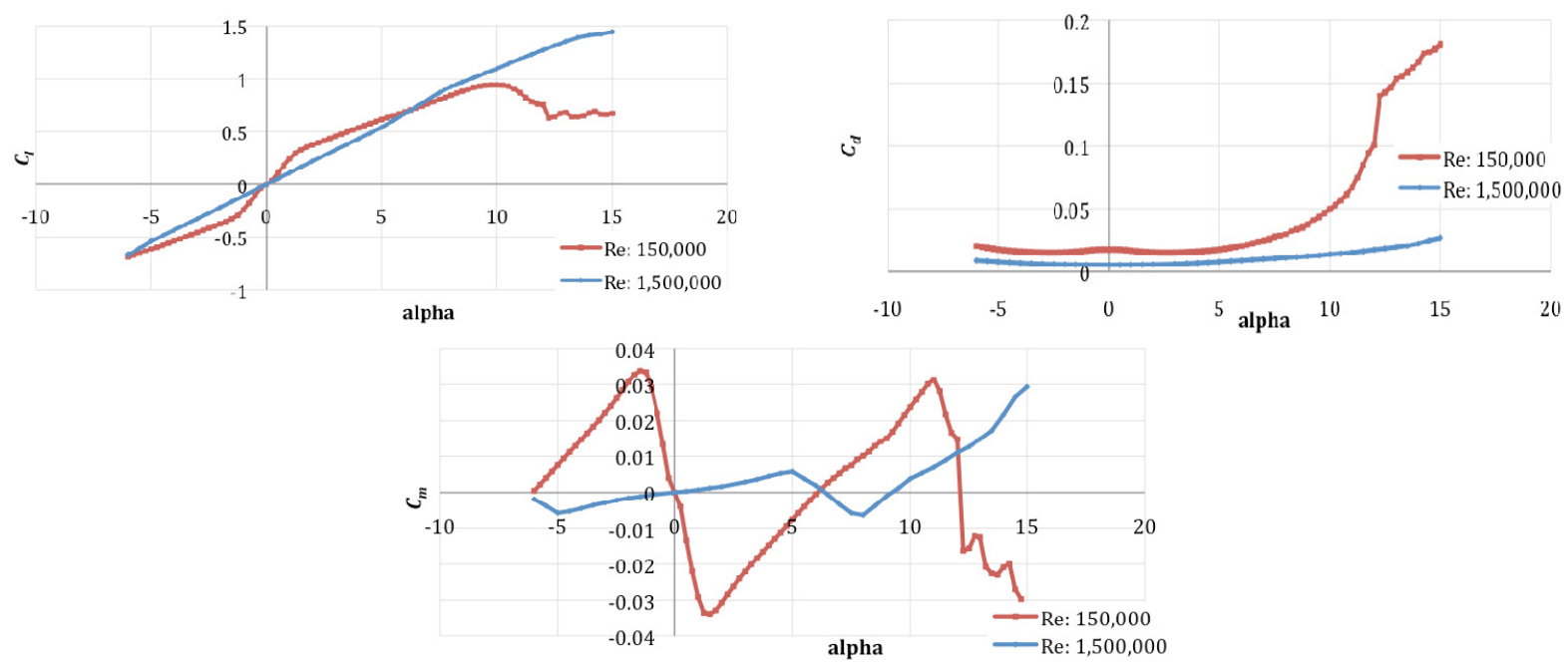

Figure 6. NACA 0012 airfoil for the horizontal tail (results obtained using Xfoil).

Table 2. EMX07 Aerodynamic Derivatives at $\mathrm{Re}=\mathbf{1 5 0 , 0 0 0}$

\begin{tabular}{|c|c|c|c|}
\hline EMX07 & $c_{l}$ & $c_{d}$ & $c_{m}$ \\
\hline Range (AOA) & & $<-0.5$ & \\
\hline$d c_{x} / d \alpha$ & 5.8034 & -0.4260 & 0.1641 \\
\hline$c_{x 0}$ & 0.0717 & 0.0065 & 0.0150 \\
\hline Range (AOA) & & $(-0.5$ to 10$)$ & \\
\hline$d c_{x} / d \alpha$ & 5.8034 & 0.0402 & 0.0815 \\
\hline$c_{x 0}$ & 0.1630 & 0.0119 & -0.0011 \\
\hline Range $(A O A)$ & & $>10$ & \\
\hline$d c_{x} / d \alpha$ & -0.2521 & 0.7739 & -0.2020 \\
\hline$c_{x 0}$ & 1.1944 & -0.1162 & 0.0572 \\
\hline
\end{tabular}

Table 3. NACA 0012 Aerodynamic Derivatives at $R e=150,000$

\begin{tabular}{|c|c|c|c|}
\hline NACA 0012 & $c_{l}$ & $c_{d}$ & $c_{m}$ \\
\hline Range $(A O A)$ & 0 to 1.5 & & 0 to 1.5 \\
\hline$d c_{x} / d \alpha$ & 12.0145 & & -1.2930 \\
\hline$c_{x 0}$ & 0.0000 & & 0.0000 \\
\hline Range (AOA) & 1.5 to 10 & 0 to 10 & 1.5 to 10 \\
\hline$d c_{x} / d \alpha$ & 4.4746 & & 0.4119 \\
\hline$c_{x 0}$ & 0.2240 & 0.0160 & -0.0435 \\
\hline A & & 32.400 & \\
\hline B & & -1.306 & \\
\hline C & & -0.024 & \\
\hline Range (AOA) & & $>10$ & \\
\hline$d c_{x} / d \alpha$ & 0.0000 & 1.6085 & -0.8318 \\
\hline$c_{x \theta}$ & 0.6000 & -0.2359 & 0.1850 \\
\hline
\end{tabular}

\section{Center Tail for Unstable Motion Arrestment}

In a flight test of X-HALE, the aeroelastic and flight dynamic data will be collected once the instability is excited. After that, the unstable motion of the aircraft needs to be arrested before it risks loss of the aircraft. As will be detailed in the numerical simulation, the unstable motion can be excited by the anti-symmetric aileron deflections 
on the dihedral wing members. The unstable motion is a combination of Dutch-roll and wing bending. Although different approaches could be used to arrest the unstable motion, a simple one-button solution that does not involve the pilot trying to fly the airplane is desirable. For that, a fifth center tail is attached to the aircraft, whose initial position is horizontal. This horizontal surface will be able to flip up vertically at the time when the unstable motion needs to be arrested. The vertical surface should provide enough lateral damping to bring the airplane back to a straight level flight condition without the pilot's interference. Figure 7 illustrates the X-HALE aircraft with a flipping center tail.

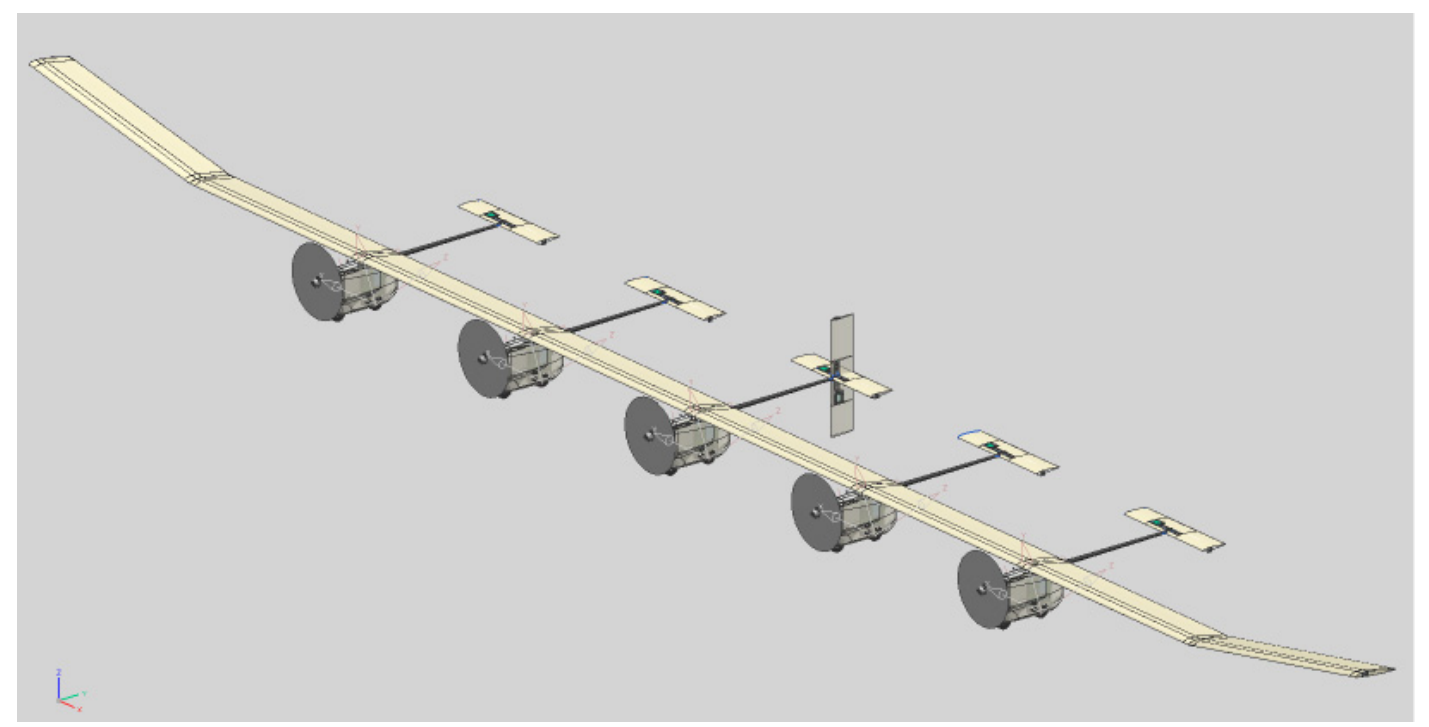

Figure 7. Center tail of X-HALE with flipping-up capability.

\section{Numerical Aeroelastic Simulation of X-HALE}

A numerical model of X-HALE was created in UM/NAST. Nonlinear aeroelastic simulations will be performed with this model to support the design and provide guidance to the flight test of X-HALE vehicle. In this section, an unstable motion of X-HALE will be firstly simulated with the excitation in the aileron deflections, flowed by the arrestment of this motion.

\section{A. Platform Data}

The 8-m space model of X-HALE is shown in Fig. 8. The outer 1-m long members feature a dihedral angle of $10^{\circ}$. Five pods are modeled as vertical lifting surfaces with applied follower concentrated forces to simulate the motor thrusts. Four tails, each with a span of $0.475 \mathrm{~m}$, are modeled as all-movable horizontal surfaces. Member properties are listed in Tables 4 and 5. Note that the booms, tails, and pods are models as rigid members, and no rigidity properties are provided for them. Ailerons are modeled on the outer dihedral members, which occupy $25 \%$ of the chord. The inertias of the spine and covers of the pods are neglected, while concentrated inertias are attached inside the pods, which come from mainly the electronic equipment.

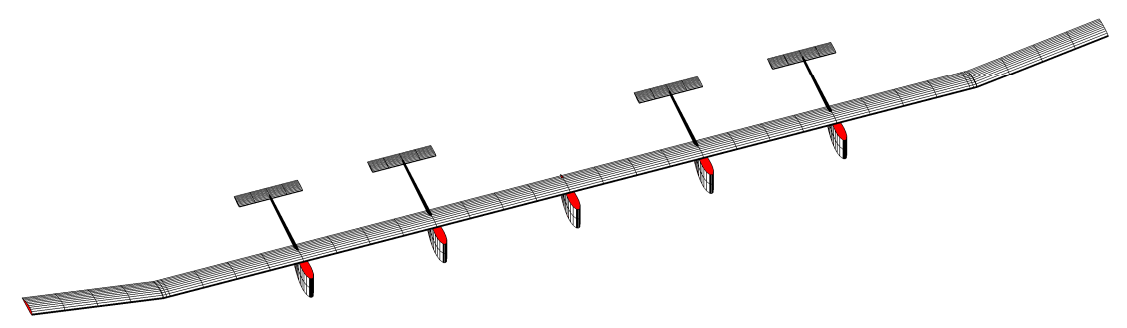

Figure 8. UM/NAST model of the X-HALE aircraft. 
Table 4. Member properties of the X-HALE model

\begin{tabular}{|c|c|c|c|c|c|}
\hline & Wing & Booms & Tails & Pods & Units \\
\hline Reference axis location (from L.E.) & 28.78 & 50 & 32.35 & 60.93 & $\%$ chord \\
\hline Center of gravity (from L.E.) & 25 & 50 & 25 & 25 & $\%$ chord \\
\hline Incidence angle & 5 & N/A & 0 & 0 & $\operatorname{deg}$ \\
\hline Chord length $(c)$ / Diameter $(d)$ & 0.20 & $\begin{array}{c}0.024 \text { (front) } \\
0.013 \text { (rear) }\end{array}$ & 0.11 & 0.37 & $\mathrm{~m}$ \\
\hline Mass per unit span $(m)$ & 0.319 & 0.01 & 0.129 & -- & $\mathrm{kg} / \mathrm{m}$ \\
\hline Rotational inertia $\left(I_{\mathrm{xx}}\right)$ & $8.09 \times 10^{-4}$ & $2.91 \times 10^{-9}$ & $1.60 \times 10^{-4}$ & -- & $\mathrm{kg} \cdot \mathrm{m}$ \\
\hline Rotational/flat bend inertia $\left(I_{\mathrm{xy}}\right)$ & 0 & 0 & 0 & -- & $\mathrm{kg} \cdot \mathrm{m}$ \\
\hline Rotational/ in-plane bend inertia $\left(I_{\mathrm{xz}}\right)$ & 0 & 0 & 0 & -- & $\mathrm{kg} \cdot \mathrm{m}$ \\
\hline Flat bend inertia $\left(I_{\mathrm{yy}}\right)$ & $1.22 \times 10^{-5}$ & $1.46 \times 10^{-9}$ & $2.91 \times 10^{-6}$ & -- & $\mathrm{kg} \cdot \mathrm{m}$ \\
\hline Flat/in-plane bend inertia $\left(I_{\mathrm{yz}}\right)$ & $-6.49 \times 10^{-6}$ & 0 & 0 & -- & $\mathrm{kg} \cdot \mathrm{m}$ \\
\hline In-plane bend inertia $\left(I_{\mathrm{zz}}\right)$ & $7.97 \times 10^{-4}$ & $1.46 \times 10^{-9}$ & $1.57 \times 10^{-4}$ & -- & $\mathrm{kg} \cdot \mathrm{m}$ \\
\hline Extensional stiffness $\left(k_{11}\right)$ & $2.14 \times 10^{6}$ & -- & -- & -- & $\mathrm{N}$ \\
\hline Extensional/torsion stiffness $\left(k_{12}\right)$ & 0 & -- & -- & -- & $\mathrm{N}$ \\
\hline Extensional/ flat bend stiffness $\left(k_{13}\right)$ & $1.54 \times 10^{3}$ & -- & -- & -- & $\mathrm{N}$ \\
\hline Extensional/in-plane bend stiffness $\left(k_{14}\right)$ & $-4.91 \times 10^{4}$ & -- & -- & -- & $\mathrm{N}$ \\
\hline Torsional stiffness $\left(k_{22}\right)$ & 72.25 & -- & -- & -- & $\mathrm{N} \cdot \mathrm{m}^{2}$ \\
\hline Torsional /flat bend stiffness $\left(k_{23}\right)$ & 0 & -- & -- & -- & $\mathrm{N} \cdot \mathrm{m}^{2}$ \\
\hline Torsional /in-plane bend stiffness $\left(k_{24}\right)$ & 0 & -- & -- & -- & $\mathrm{N} \cdot \mathrm{m}^{2}$ \\
\hline Flat bend stiffness $\left(k_{33}\right)$ & 119.57 & -- & -- & -- & $\mathrm{N} \cdot \mathrm{m}^{2}$ \\
\hline Flat/in-plane bend stiffness $\left(k_{34}\right)$ & -46.34 & -- & -- & -- & $\mathrm{N} \cdot \mathrm{m}^{2}$ \\
\hline In-plane bend stiffness $\left(k_{44}\right)$ & $6.35 \times 10^{3}$ & -- & -- & -- & $\mathrm{N} \cdot \mathrm{m}^{2}$ \\
\hline
\end{tabular}

Table 5. List of the concentrated inertias of the X-HALE model

\begin{tabular}{|c|c|c|c|c|c|c|c|c|c|}
\hline & \multicolumn{3}{|c|}{ Outboard pods } & \multicolumn{3}{|c|}{ Center pod } & \multirow[b]{2}{*}{$\begin{array}{c}\text { Inner half } \\
\text { tail }\end{array}$} & \multirow[b]{2}{*}{$\begin{array}{c}\text { Outer half } \\
\text { tail }\end{array}$} & \multirow[b]{2}{*}{ Units } \\
\hline & $\begin{array}{c}\text { Battery } \\
\text { forward cg }\end{array}$ & $\begin{array}{c}\text { Battery } \\
\text { aft cg }\end{array}$ & $\begin{array}{c}\text { Remaining } \\
\text { assembly }\end{array}$ & $\begin{array}{c}\text { Battery } \\
\text { forward cg }\end{array}$ & $\begin{array}{c}\text { Battery } \\
\text { aft cg }\end{array}$ & $\begin{array}{c}\text { Remaining } \\
\text { assembly }\end{array}$ & & & \\
\hline mass & 0.396 & 0.396 & 1.057 & 0.396 & 0.396 & 1.025 & 0.049 & 0.020 & $\mathrm{~kg}$ \\
\hline$x_{c g}^{*}$ & 0.013 & 0.013 & -0.006 & 0.013 & 0.013 & -0.003 & 0.073 & 0.029 & $\mathrm{~m}$ \\
\hline$y_{c g}$ & 0.059 & -0.001 & 0.066 & 0.059 & -0.001 & 0.043 & -0.008 & 0 & $\mathrm{~m}$ \\
\hline$z_{c g}$ & -0.069 & -0.069 & -0.085 & -0.069 & -0.069 & -0.080 & -0.001 & 0 & $\mathrm{~m}$ \\
\hline$I_{x x}$ & \multicolumn{2}{|c|}{$1.160 \times 10^{-3}$} & $1.134 \times 10^{-2}$ & \multicolumn{2}{|c|}{$1.160 \times 10^{-3}$} & $1.476 \times 10^{-2}$ & $4.631 \times 10^{-6}$ & $1.866 \times 10^{-7}$ & $\mathrm{~kg} \cdot \mathrm{m}^{2}$ \\
\hline$I_{y y}$ & \multicolumn{2}{|c|}{$9.485 \times 10^{-5}$} & $3.209 \times 10^{-3}$ & \multicolumn{2}{|c|}{$9.485 \times 10^{-5}$} & $2.816 \times 10^{-3}$ & $2.282 \times 10^{-5}$ & $1.341 \times 10^{-6}$ & $\mathrm{~kg} \cdot \mathrm{m}^{2}$ \\
\hline$I_{z z}$ & \multicolumn{2}{|c|}{$1.098 \times 10^{-3}$} & $8.484 \times 10^{-3}$ & \multicolumn{2}{|c|}{$1.098 \times 10^{-3}$} & $2.503 \times 10^{-4}$ & $2.651 \times 10^{-5}$ & $1.311 \times 10^{-6}$ & $\mathrm{~kg} \cdot \mathrm{m}^{2}$ \\
\hline$I_{x y}$ & \multicolumn{2}{|c|}{0} & $-1.212 \times 10^{-3}$ & \multicolumn{2}{|c|}{0} & $2.322 \times 10^{-4}$ & $-3.190 \times 10^{-6}$ & $1.000 \times 10^{-10}$ & $\mathrm{~kg} \cdot \mathrm{m}^{2}$ \\
\hline$I_{x z}$ & \multicolumn{2}{|c|}{0} & $1.055 \times 10^{-5}$ & \multicolumn{2}{|c|}{0} & $2.267 \times 10^{-5}$ & $-3.057 \times 10^{-7}$ & 0 & $\mathrm{~kg} \cdot \mathrm{m}^{2}$ \\
\hline$I_{y z}$ & \multicolumn{2}{|c|}{0} & $4.595 \times 10^{-5}$ & \multicolumn{2}{|c|}{0} & $4.500 \times 10^{-4}$ & $2.644 \times 10^{-8}$ & 0 & $\mathrm{~kg} \cdot \mathrm{m}^{2}$ \\
\hline
\end{tabular}

\section{B. Achievement of the Unstable Motion of X-HALE}

The first step of the simulation is to achieve an unstable motion that couples the rigid-body motion of the whole aircraft and the elastic wing deformations. In this simulation, the anti-symmetric inputs for the elevons (ailerons) on the dihedral wing members are used to actuate roll motions of the aircraft. Eq. (1) exemplifies the aileron deflection angle on the left wing.

\footnotetext{
* The c.g. locations are measured from the root of each member, i.e., the top surfaces for the pod members and the connection point with the boom for the tail members.
} 


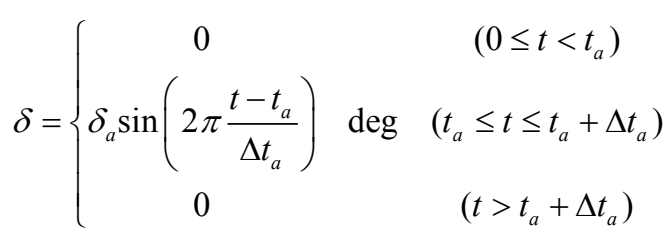

where $t_{a}=2 \mathrm{~s}$ and $\Delta t_{a}=2 \mathrm{~s}$, indicating ailerons start to deflect after $2 \mathrm{~s}$ into the simulation, and complete one sinusoidal cycle within the next two seconds. The maximum magnitude of the aileron deflection $\delta_{a}$ is $10^{\circ}$. Figures 9 to 14 compare the flight of the X-HALE model with such an aileron actuation against the level flight without aileron actuation. Note that the vehicle starts its flight with the pre-trimmed condition for the level flight. No other control input is applied to it, except for the aileron actuation. From the plots, one can clearly see an unstable Dutch-roll motion of the aircraft is excited (Figs. 12 and 14). The Dutch-roll motion is also coupled with the bending of the flexible wings (Fig. 15). This will be the target mode to be tested and measured during the flight test. Note that after $18 \mathrm{~s}$, the simulation encounters difficulties in obtaining a converged solution in the numerical integration, because of the large rigid-body motion of the aircraft.

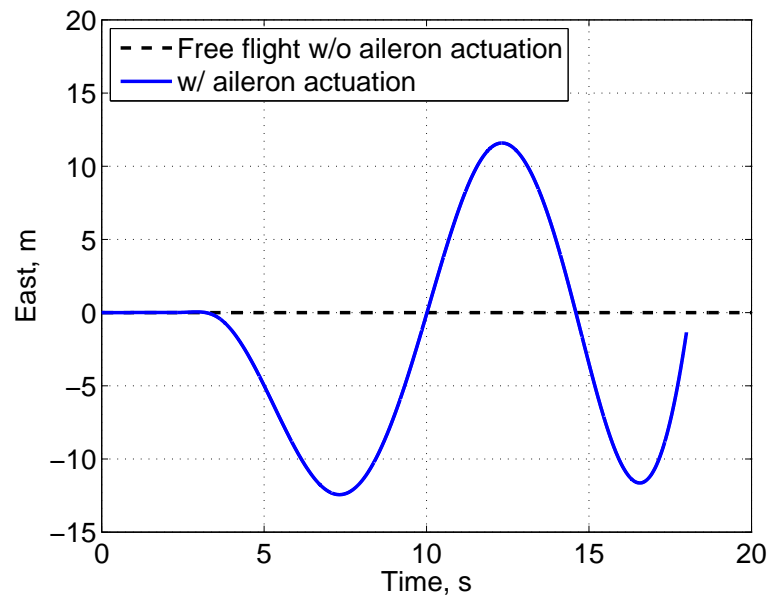

Figure 9. Lateral position of X-HALE with aileron actuation.

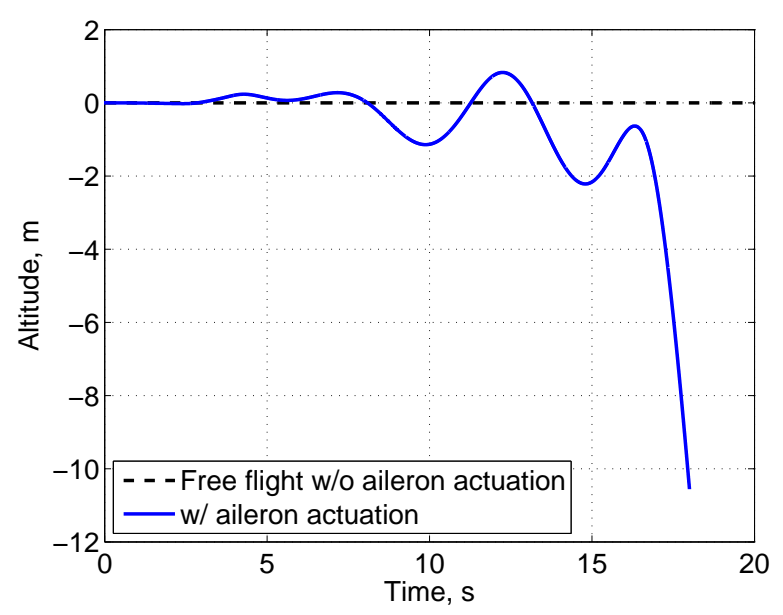

Figure 11. Altitude of X-HALE with aileron actuation.

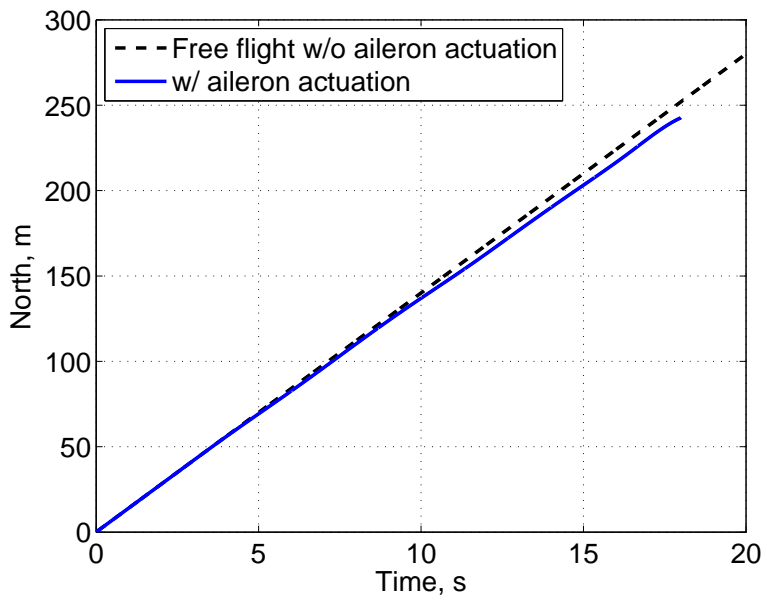

Figure 10. Longitudinal position of X-HALE with aileron actuation.

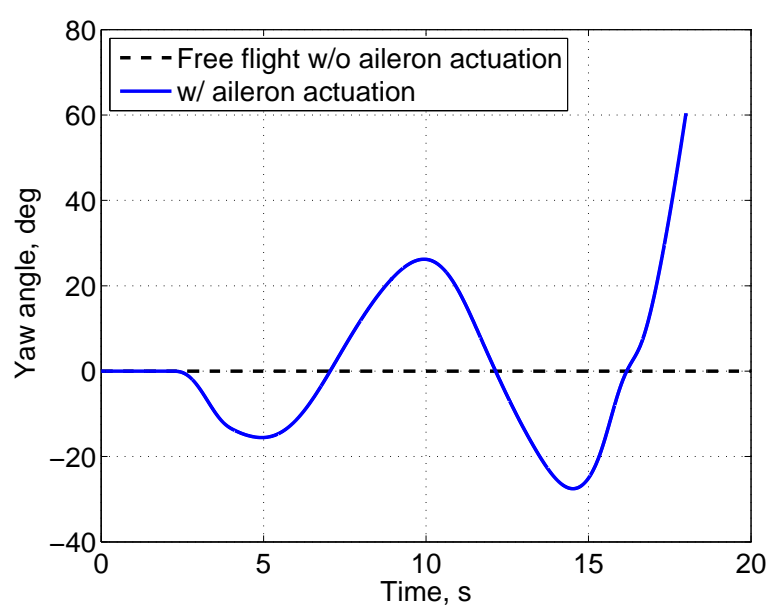

Figure 12. Yaw angle of $X-H A L E$ with aileron actuation. 


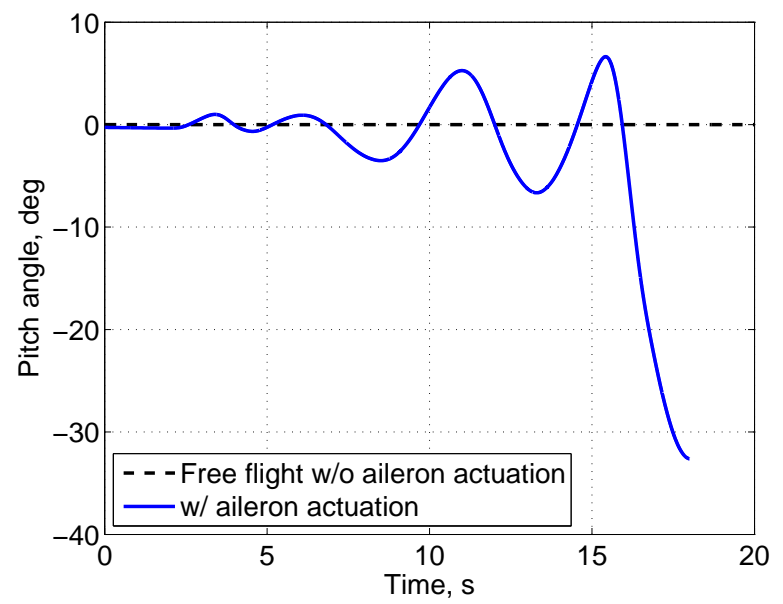

Figure 13. Pitch angle of X-HALE with aileron actuation.

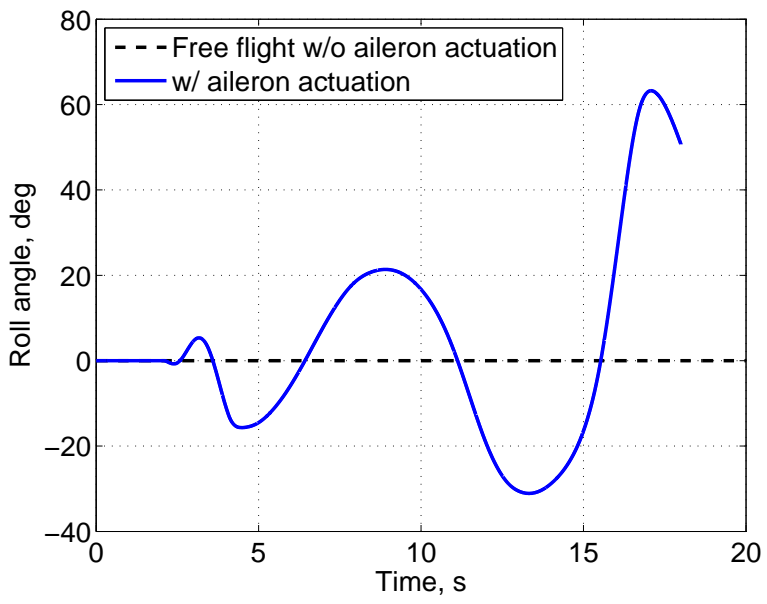

Figure 14. Roll angle of X-HALE with aileron actuation.

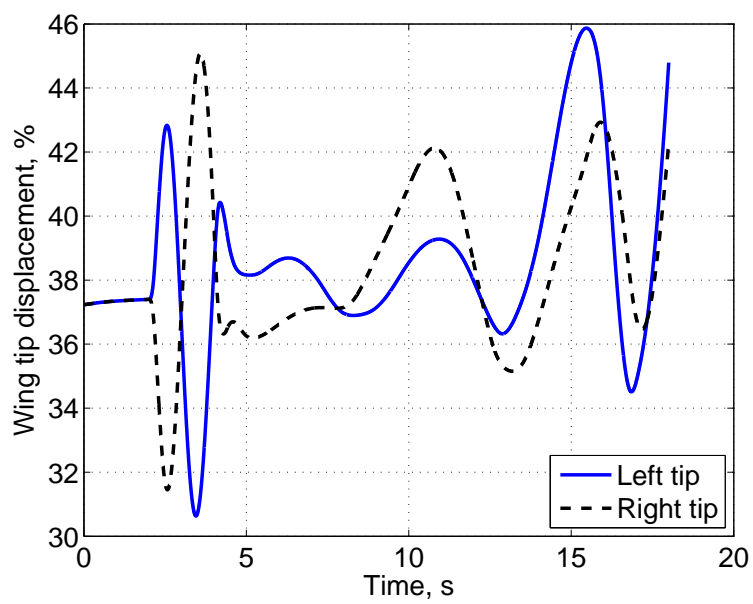

Figure 15. Tip displacements of X-HALE with aileron actuation (normalized with respect to the half span of aircraft).

\section{Stabilization of X-HALE's Unstable Motion}

Once the unstable Dutch-roll motion of X-HALE is excited during the flight, the aeroelastic and flight dynamic data will be measured with the on-board sensors. Then, the unstable motion needs to be arrested because of the risk in losing the aircraft. A simple push-button approach is used in the current work without complex pilot control. For this, an additional center tail is built to the vehicle. This horizontal surface can flip up vertically at the time when the unstable motion needs to be arrested. The X-HALE model in UM/NAST with a center tail is shown in Fig. 16. The flipping motion of the center tail is determined by

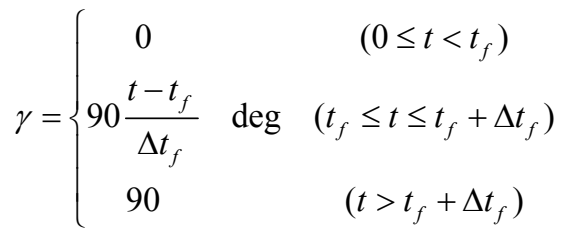

where $t_{f}=12 \mathrm{~s}$ and $\Delta t_{f}=0.5 \mathrm{~s}$. Note that the positive direction of $\gamma$ is defined as right half tail flipping down. In attempt to allow the vertical tail to be present while taking off, the right half of the center tail needs to be cut short to 
satisfy the ground clearance. This makes the center tail asymmetric. The resulting dimension of the center tail is compared to that of the outer tails in Table 6.

Table 6. List of X-HALE tail dimensions.

\begin{tabular}{lllc}
\hline \hline & & Span & Unit \\
\hline \multirow{2}{*}{ Outer tails } & Inner half tail & 0.2375 & $\mathrm{~m}$ \\
\cline { 2 - 4 } & Outer half tail & 0.2375 & $\mathrm{~m}$ \\
\hline \multirow{2}{*}{ Center tail } & Left half tail & 0.2375 & $\mathrm{~m}$ \\
\cline { 2 - 4 } & Right half tail & 0.1750 & $\mathrm{~m}$ \\
\hline \hline
\end{tabular}

Figures 17 to 22 compare the behaviors of the X-HALE model with and without the flipping center tail. After 12 $\mathrm{s}$, the center tail flips up vertically within $0.5 \mathrm{~s}$. From this on, the magnitude of the Dutch-roll motion decreases because of the additional lateral damping introduced by the center vertical surface (Figs. 20 and 22). The oscillation of the vehicle in other directions such as plunging (Fig. 19) and pitching (Fig. 21) are also arrested. The vehicle is brought back to level flight. Figure 23 indicates the magnitude of the wing bending oscillation also decreases after the center tail flips up. Therefore, the approach introduced here to arrest the vehicle's unstable motion is effective. Note that the center tail is asymmetric. However, due to the closeness of the tail force to the center axis of the vehicle, any roll moment caused by the asymmetry is negligible, as shown in the early stages of the flight, when no aileron actuation is applied (Fig. 22, before $2 \mathrm{~s}$ ).

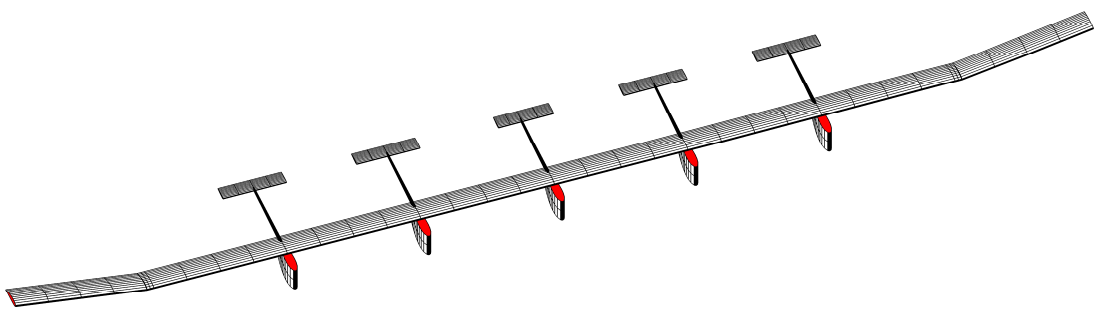

Figure 16. UM/NAST model of the X-HALE aircraft with the center tail.

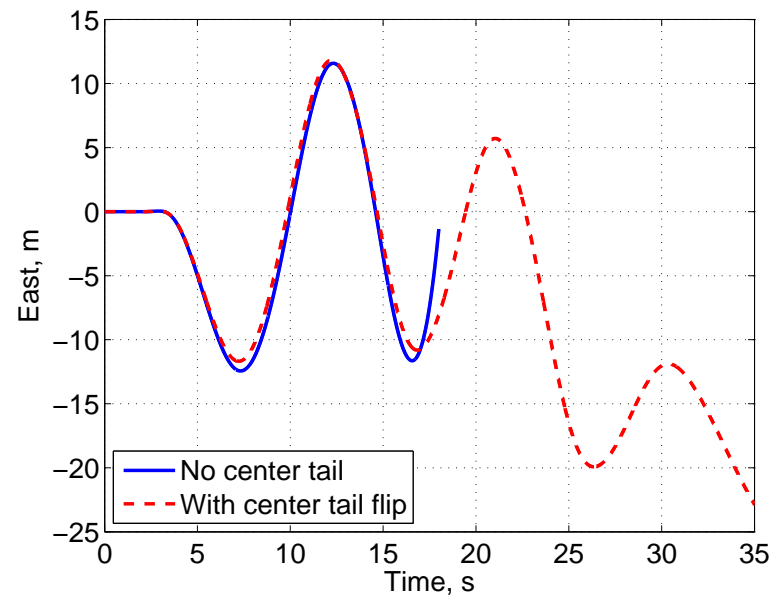

Figure 17. Lateral position of X-HALE with center tail flip.

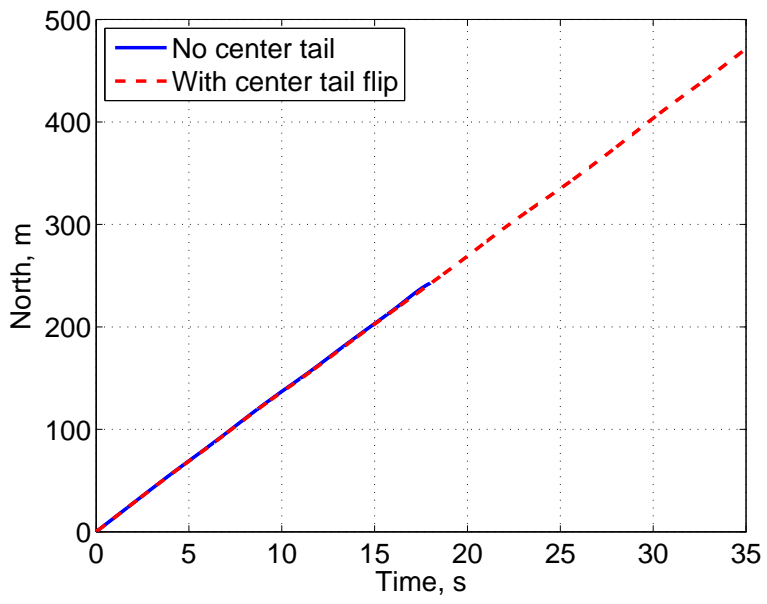

Figure 18. Longitudinal position of X-HALE with center tail flip. 

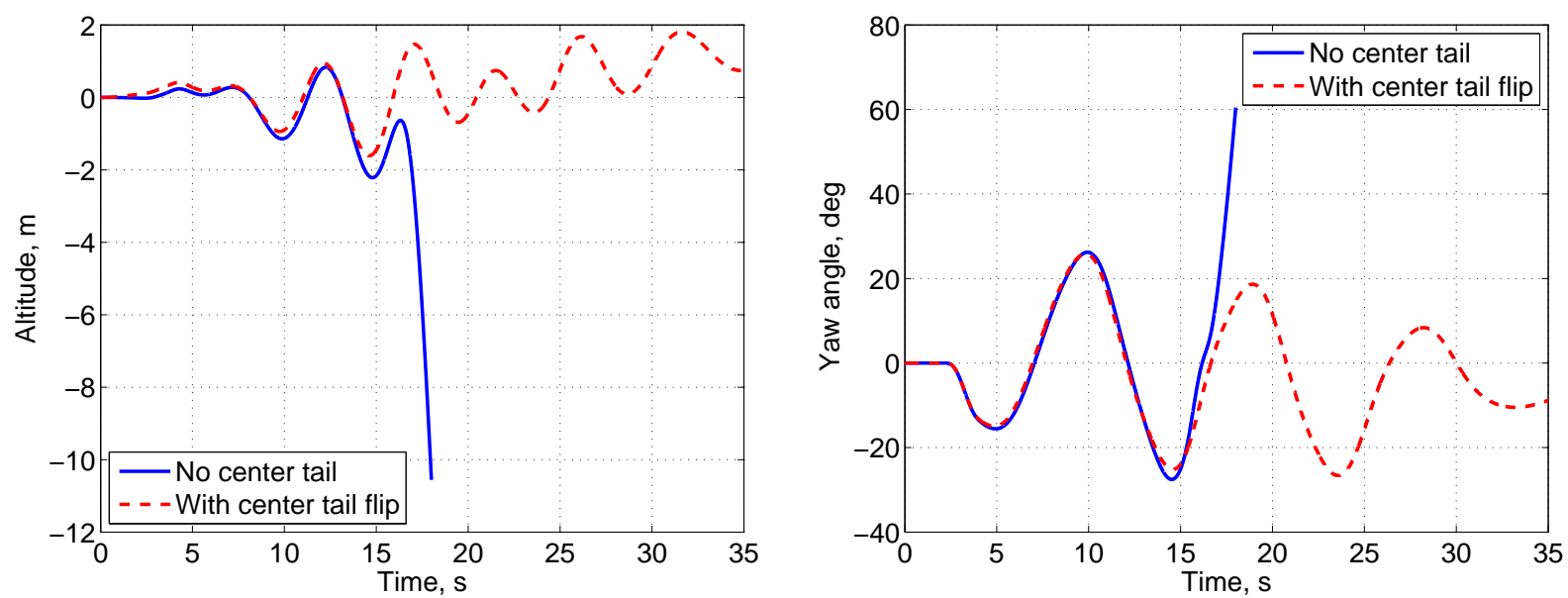

Figure 19. Altitude of X-HALE with center tail flip. Figure 20. Yaw angle of X-HALE with center tail flip.
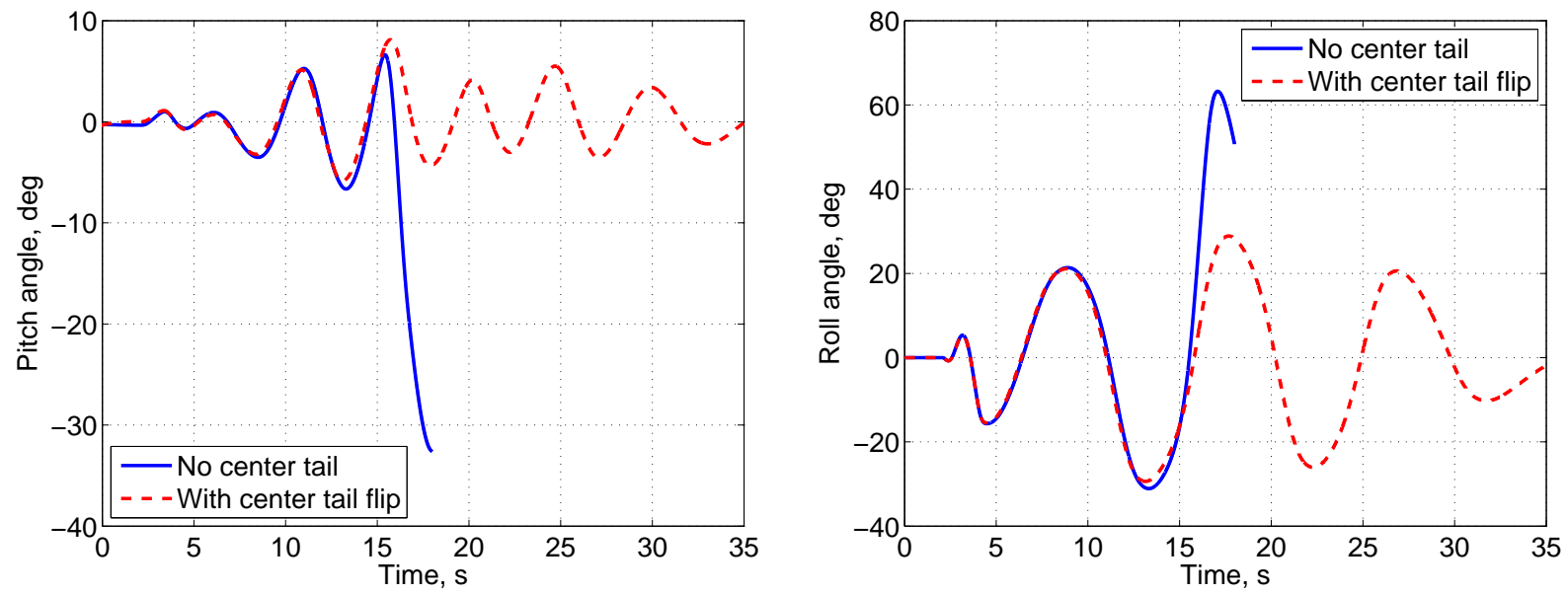

Figure 21. Pitch angle of X-HALE with center tail flip. Figure 22. Roll angle of X-HALE with center tail flip.
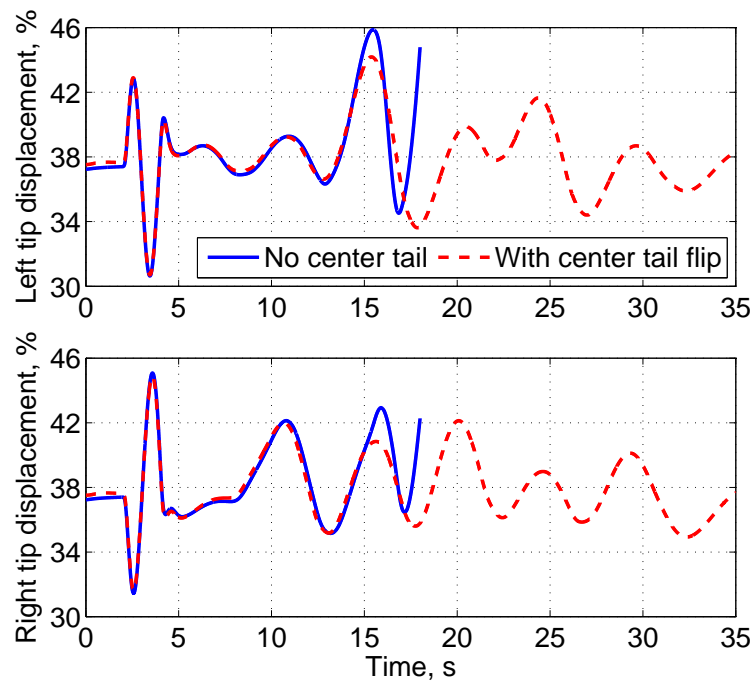

Figure 23. Comparison of tip displacements of X-HALE (normalized with respect to the half span of aircraft). 


\section{Concluding Remarks}

This paper provided an overview of the X-HALE UAV as a test bed for nonlinear aeroelastic flight tests, which has been developed in University of Michigan in collaboration with Air Force Institute of Technology and Air Force Research Laboratory. The very flexible aircraft was designed to demonstrate coupled nonlinear aeroelastic/flight dynamic behavior with finite control surface excitations. The flight test will provide valuable data to support validation of numerical formulations developed for coupled nonlinear aeroelastic and flight dynamic analysis of future very flexible aircraft.

As guidance to the aeroelastic design process, a numerical model of the 8-m span configuration of X-HALE was created in UM/NAST, and its aeroelastic behavior was studied through the coupled nonlinear aeroelastic and flight dynamic simulations. To induce an unstable motion, anti-symmetric aileron deflections were used. As was seen from the simulation results, a finite aileron deflection could excite unstable Dutch-roll motion coupled with wing flexible bending modes. This indicated a possible test point to be explored during flight tests and for which wind tunnel tests would not be feasible. To arrest the instability, an additional center tail was used. The center tail could flip up and provide extra damping to the roll motion. Therefore, the oscillation of the Dutch-roll motion was eventually damped out, and the aircraft was brought back to straight level flight.

\section{Acknowledgments}

This work has been supported by the Air Force Research Laboratory under the Michigan/AFRL Collaborative Center in Aeronautical Sciences (MACCAS). The technical monitor is Dr. Edward Alyanak (AFRL). Additional funds were also provided by the University of Michigan's Active Aeroelasticity and Structures Research Laboratory.

\section{References}

${ }^{1}$ Tilmann, C. P., Flick, P. M., Martin, C. A. and Love, M. H., "High-Altitude Long Endurance Technologies for SensorCraft," MP-104-P-26, RTO AVT-099 Symposium on Novel and Emerging Vehicle and Vehicle Technology Concepts, Brussels, Belgium, Apr. 7-11, 2003.

${ }^{2}$ Whitson, S., "The Proteus, Giving Shape to Forms Unknown,” Private Pilot, Vol. 33, No. 12, 1998, pp. 44-50.

${ }^{3}$ Palacios, R. and Cesnik, C. E. S., "A Re-examination of the Structural Design Procedures for Very Flexible Aircraft," International Forum on Aeroelasticity and Structural Dynamics 2007, Stockholm, Sweden, June 18-21, 2007.

${ }^{4}$ Wilson, J. R., "Fly Like a Vulture," Aerospace America, Vol. 46, No. 11, 2008, pp. 28-33.

${ }^{5}$ Noll, T. E., Brown, J. M., Perez-Davis, M. E., Ishmael, S. D., Tiffany, G. C. and Gaier, M., "Investigation of the Helios Prototype Aircraft Mishap. Volume 1: Mishap Report," 2004.

${ }^{6}$ US Army Aviation and Missile Command, RCAS User's Manual, Version 2.0, Moffett Field, CA.

${ }^{7}$ Drela, M., "Integrated Simulation Model for Preliminary Aerodynamic, Structural, and Control-Law Design of Aircraft," AIAA-1999-1394, 40th AIAA / ASME / ASCE / AHS / ASC Structures, Structural Dynamics, and Materials Conference and Exhibit, St. Louis, MO, Apr. 12-15, 1999.

${ }^{8}$ Cesnik, C. E. S. and Brown, E. L., "Modeling of High Aspect Ratio Active Flexible Wings for Roll Control," AIAA-20021719, 43rd AIAA / ASME / ASCE / AHS / ASC Structures, Structural Dynamics, and Materials Conference, Denver, CO, Apr. 22$25,2002$.

${ }^{9}$ Cesnik, C. E. S. and Su, W., "Nonlinear Aeroelastic Modeling and Analysis of Fully Flexible Aircraft," AIAA-2005-2169, 46th AIAA / ASME / ASCE / AHS / ASC Structures, Structural Dynamics, and Materials Conference, Austin, TX, Apr. 18-21, 2005.

${ }^{10}$ Shearer, C. M., "Coupled Nonlinear Flight Dynamics, Aeroelasticity, and Control of Very Flexible Aircraft," Ph.D. Dissertation, Department of Aerospace Engineering, The University of Michigan, Ann Arbor, MI, 2006.

${ }^{11}$ Shearer, C. M. and Cesnik, C. E. S., "Nonlinear Flight Dynamics of Very Flexible Aircraft," Journal of Aircraft, Vol. 44, No. 5, 2007, pp. 1528-1545.

${ }^{12}$ Shearer, C. M. and Cesnik, C. E. S., "Trajectory Control for Very Flexible Aircraft," Journal of Guidance, Control, and Dynamics, Vol. 31, No. 2, 2008, pp. 340-357.

${ }^{13}$ Patil, M. J., Hodges, D. H. and Cesnik, C. E. S., "Nonlinear Aeroelasticity and Flight Dynamics of High-Altitude LongEndurance Aircraft," Journal of Aircraft, Vol. 38, No. 1, 2001, pp. 88-94.

${ }^{14}$ Patil, M. J. and Hodges, D. H., "Flight Dynamics of Highly Flexible Flying Wings," Journal of Aircraft, Vol. 43, No. 6, 2006, pp. 1790-1798.

${ }^{15}$ Chang, C.-S., Hodges, D. H. and Patil, M. J., "Flight Dynamics of Highly Flexible Aircraft," Journal of Aircraft, Vol. 45, No. 2, 2008, pp. 538-545.

${ }^{16}$ Cesnik, C. E. S., Senatore, P., Su, W., Atkins, E., Shearer, C. M. and Pitcher, N., "X-HALE: A Very Flexible UAV for Nonlinear Aeroelastic Tests," AIAA-2010-2715, 51st AIAA / ASME / ASCE / AHS / ASC Structures, Structural Dynamics, and Materials Conference, Orlando, FL, Apr. 12-15, 2010. 
${ }^{17}$ Cesnik, C. E. S. and Brown, E. L., "Active Wing Warping Control of a Joined-Wing Airplane Configuration,” AIAA-20031715, 44th AIAA / ASME / ASCE / AHS / ASC Structures, Structural Dynamics, and Materials Conference, Norfolk, VA, Apr. 7$10,2003$.

${ }^{18}$ Brown, E. L., “Integrated Strain Actuation In Aircraft With Highly Flexible Composite Wings," Ph.D. Dissertation, Department of Mechanical Engineering, Massachusetts Institute of Technology, Cambridge, MA, 2003.

${ }^{19}$ Cesnik, C. E. S. and Ortega-Morales, M., “Active Aeroelastic Tailoring of Slender Flexible Wings,” International Forum on Aeroelasticity and Structural Dynamics 2003, Madrid, Spain, 2003.

${ }^{20} \mathrm{Su}$, W. and Cesnik, C. E. S., "Dynamic Response of Highly Flexible Flying Wings," AIAA-2006-1636, 47th AIAA / ASME / ASCE / AHS / ASC Structures, Structural Dynamics, and Materials Conference, Newport, RI, May 1-4, 2006.

${ }^{21}$ Chandra, R. and Chopra, I., "Structural Response of Composite Beams and Blades with Elastic Couplings," Composites Engineering, Vol. 2, No. 5-7, 1992, pp. 347-374.

${ }^{22}$ Minguet, P. and Dugundji, J., "Experiments and Analysis for Composite Blades Under Large Deflections Part I: Static Behavior," AIAA Journal, Vol. 28, No. 9, 1990, pp. 1573-1579.

${ }^{23}$ Minguet, P. and Dugundji, J., "Experiments and Analysis for Composite Blades Under Large Deflections Part II: Dynamic Behavior," AIAA Journal, Vol. 28, No. 9, 1990, pp. 1580-1588.

${ }^{24}$ Tang, D. and Dowell, E. H., "Experimental and Theoretical Study on Aeroelastic Response of High-Aspect-Ratio Wings," AIAA Journal, Vol. 39, No. 8, 2001, pp. 1430-1441.

${ }^{25}$ Tang, D. and Dowell, E. H., "Experimental and Theoretical Study of Gust Response for High-Aspect-Ratio Wing," AIAA Journal, Vol. 40, No. 3, 2002, pp. 419-429. 